Nunes, T. M., Flores, S. A. M. \& Silva, A, C. J. (2018). A aversão à perda e o excesso de confiança sob a ótica do gênero. Consumer Behavior Review, 2(1), 42-54.

\title{
A AVERSÃO À PERDA E O EXCESSO DE CONFIANÇA SOB A ÓTICA DO GÊNERO
}

\author{
Tamara Morel Nunes \\ Silvia Amélia Mendonça Flores \\ Ana Carolina Cozza Josende da Silva
}

Tamara Morel Nunes é Graduada em Administração pela Universidade Federal do Pampa - UNIPAMPA. E-mail: t.morel@hotmail.com.

Silvia Amélia Mendonça Flores é

Professora Assistente da Universidade

Federal do Pampa - UNIPAMPA. E-mail: silviaamflores@gmail.com.

Ana Carolina Cozza Josende da Silva é Professora do Centro Universitário

Franciscano - UNIFRA. E-mail:

anacarolina_cj@yahoo.com.br.

Os autores agracedecem aos avaliadores pelos comentários para melhoria do artigo.

\begin{abstract}
Resumo
A tomada de decisão financeira é um dos aspectos estudados pelas Finanças Comportamentais, que partem do pressuposto da racionalidade limitada dos indivíduos. Considerando especificamente os estudantes, pode-se compreender a validade dos julgamentos realizados, sendo um auxílio na atuação profissional dos mesmos. Assim, o presente estudo buscou analisar os vieses comportamentais de aversão à perda e excesso de confiança nos estudantes do Curso de Administração de uma Universidade do Rio Grande do Sul sob a ótica do gênero. 0 primeiro viés faz com que os indivíduos corram riscos mais freqüentes em suas decisões, já o segundo, faz com que os mesmos confiem mais do que deveriam em seus próprios conhecimentos e opiniões. Realizou-se uma pesquisa survey composta por 81 respondentes, a partir de um questionário estruturado, o qual abordou os vieses comportamentais e questões de perfil. Por meio da análise foi possível observar que os estudantes possuem os vieses analisados e que estes afetam a tomada de decisão. Sob a ótica do gênero, percebeu-se que não há diferença.

Palavras-chave: Aversão à perda, Excesso de confiança, Diferenças de Gênero.
\end{abstract}

Esta obra está licenciada com uma Licença Creative Commons Atribuição 4.0 Internacional.

\section{INTRODUÇÃO}

A co-criação de valor refere-se ao processo de interação entre empresa e consumidores com o objetivo de criar objetos ou serviços que tenham valor para as duas partes (Grönroos, 2000).

As finanças comportamentais formam um novo campo de estudos no Brasil que confronta o pressuposto defendido pelas finanças 
tradicionais, o da racionalidade dos tomadores de decisão (Silva et al., 2009). Lobão (2012), diz que as decisões tomadas pelo agente econômico são na realidade afetadas por fatores psicológicos, sendo que o comportamento pode afastar-se consideravelmente do presumido no campo tradicional da teoria das finanças. Ainda, há muita discussão em relação à influência desse comportamento humano na tomada de decisões financeiras, que engloba uma série de fatores comportamentais de extrema importância para a compreensão do mercado como um todo.

Nesse contexto, alguns estudiosos (Kahneman \& Tversky, 1979) buscaram elaborar modelos econômicos que considerem o fato de que o homem não é completamente racional, cujo grande desafio está confrontado com a vasta complexidade da irracionalidade humana.Partindo racionalidade limitada, surgem diversos vieses comportamentais, tais como, otimismo, excesso de confiança, ancoragem, representatividade, entre vários outros que podem influenciar, tanto de forma positiva como negativa no processo decisório, ou até mesmo não influenciar.

Lobão (2012) ressalta que o crescimento dos mercados econômicos ao longo das últimas décadas, a relevância da participação de investidores individuais, assim como, o desenvolvimento de novos produtos financeiros é o incentivo para que se estude a maneira como os agentes econômicos decidem. Ainda, de acordo com o autor, a importância do estudo das decisões financeiras individuais é estimulada por duas hipóteses. A primeira é o fato de existirem muitas circunstâncias em que os indivíduos tomam decisões de forma isolada, sem contar com qualquer auxílio. A segunda, é que as finanças comportamentais argumentam que os agentes com racionalidade limitada podem influenciar o mercado financeiro.

Neste contexto, este estudo tem como objetivo analisar os vieses comportamentais aversão à perda e excesso de confiança nos estudantes do Curso de Administração de uma Universidade do Rio Grande do Sul sob a ótica do gênero.Considera-se relevante a investigação dos estudantes, tendo em vista que em algum momento de sua atuação profissional, os mesmos terão que tomar decisões que podem envolver ganhos e perdas, uma vez que as decisões constituem a base da formação pessoal e profissional dos agentes. Particularmente, na área de Administração, os estudantes devem estar preparados para atuar com recursos financeiros e humanos, necessitando otimizar suas escolhas.

Além disso, os estudantes atuam com projeções passadas, atuais e futuras, sendo que julgamentos equivocados quanto a acontecimentos futuros poderão acarretar equívocos (Mendes-da-Silva \& Yu, 2009), visto que são afetados pelas expectativas dos agentes, inclusive, pelo excesso de confiança.No que tange a relevância do estudo em âmbito pessoal, tem-se o conhecimento do perfil dos estudantes, podendo desenvolver estratégias que qualifiquem a decisão pessoal. Soares e Barbedo (2013) também constataram que o Desempenho Acadêmico apresentarelação com a racionalidade de escolhas e altera a ação dos vieses cognitivos sobre o processo decisóriodos agentes. Os discentes com desempenho acadêmico superior realizaram escolhas mais racionaisque os demais estudantes.

Uma melhor compreensão dos erros de cognição que afetam o comportamento dos indivíduos, forma um argumento essencial para esclarecer fenômenos financeiros. Tais como, guiar a constituição de políticas públicas e também fundamentar a implantação de estratégias de ação para as organizações (Mendes-da-Silva \& Yu, 2009). Desta forma, o presente trabalho busca contribuir para a área de finanças comportamentais, apresentando evidências empíricas e reflexões sobre o comportamento dos estudantes, que futuramente, estarão ocupando cargos de gestores nas empresas, e decidindo em um cenário com variáveis exógenas e endógenas, e em constante mutação.

Quanto ao gênero, destaca-se a importância de analisar as diferenças comportamentais apontadas pela literatura. Conforme Zuckerman e Kuhlman (2000) e Keese (2010), as mulheres possuem uma percepção de risco mais elevada do que os homens, fazendo com que tenham, geralmente, um comportamento de risco mais conservador. Levando em consideração a funçãode valor hipotética, desenvolvida por Kahneman e Tversky (1979) em sua Teoria do Prospecto, os indivíduossão avessos ao risco para ganhos, mas propensos ao risco para perdas. Por isso, a análise do gênero permitirá um comparativo com os pressupostos teóricos. 


\section{FINANÇAS COMPORTAMENTAIS}

A Moderna Teoria de Finanças considera que no mercado somente os agentes racionais sobrevivem, já os agentes irracionais são expulsos do mesmo pelos racionais. Para complementar esse paradigma e o das finanças tradicionais que pressupõem a racionalidade dos agentes econômicos, surge a Teoria das Finanças Comportamentais, partindo do pressuposto de que os agentes econômicos possuem uma racionalidade limitada. A ideia básica das finanças comportamentais não é rejeitar todos os aspectos das finanças modernas ou tradicionais, mas sim aperfeiçoar os modelos financeiros através da incorporação de tendências de comportamento detectadas nos humanos (Macedo Jr., Kolinsky \& Morais, 2011).

As finanças comportamentais conforme Lobão (2012), ao invés de defender uma visão idealizada da realidade prevista no campo das finanças tradicionais, sugere uma visão mais realista das decisões tomadas pelos agentes econômicos e investidores. Para Statman (2014), finanças comportamentais está em construção e expande o campo de estudos tradicionais, pois estabelece vínculos entre teoria, evidência e prática. Em suma, busca estudar o como e o porquê dos agentes econômicos se comportarem da maneira que de fato se comportam. No estudo desse comportamento, percorre-se com frequência a outras ciências, em particular a psicologia, considerando que as decisões tomadas pelos agentes econômicos são afetadas por fatores psicológicos e sociológicos (Kimura, 2003).

Diante deste contexto da evolução dos estudos em finanças, cabe ressaltar que as pesquisas em finanças comportamentais são basicamente fundamentadas nos estudos de dois psicólogos israelenses, Amos Tversky e Daniel Kahneman, sendo o último gratificado com o Prêmio Nobel de Economia de 2002, através de seus trabalhos realizados entre os anos de 1974 e 1979 que tiveram importância seminal e constituíram o alicerce teórico das finanças comportamentais. Entretanto, foi através do trabalho de Richard Thaler que este campo de estudos se consolidou (Macedo Jr., 2003).

Ramos (2007) elucida que a temática está relacionada diretamente à identificação e classificação dos vieses comportamentais que dizem respeito as emoções e aos erros cognitivos que tem a capacidade de exercer influência no processo decisório e consequentemente afastar as pessoas da racionalidade ilimitada. Corroborando com esta visão, Kahneman (2012, p. 10) destaca que: "erros sistemáticos de avaliação são conhecidos como vieses e se repetem de forma previsível em circunstâncias particulares". Já Pompian (2006) considera os erros sistemáticos como heurísticas, crenças, julgamentos, preferências ou linhas cognitivas e emocionais.

Segundo Araújo e Silva (2007) esses vieses no processo decisório humano afrontam teorias econômicas que possuem como pressuposto a racionalidade dos agentes, procurando explicar de um modo mais verdadeiro, as anomalias existentes no mercado financeiro.Nas finanças padrão tem-se a atuação dos investidores racionais, caracterizados como livres de erros cognitivos e emoções que podem levar a tomada de decisão distorcida. Por outro lado, finanças comportamentais acredita no investidor normal, que ao contrário dos racionais pode estar propenso a erros cognitivos e emoções enganosas (Statman, 2014). A seguir serão abordados os vieses aversão à perda e excesso de confiança que são o foco deste trabalho.

\section{Aversão à perda}

Este viés é decorrente da Teoria do Prospecto, na qual Kahneman e Tversky (1979) sustentam que os indivíduos sentem muito mais a dor da perda do que o prazer obtido por um ganho semelhante. Esta teoria se opõe ao conceito microeconômico denominado Teoria da Utilidade Esperada (TUE), onde a escala u mensurava a utilidade de resultados a partir do grau de riqueza do indivíduo. A Teoria do Prospecto, por sua vez, mensura a função valor a partir de um ponto de referência e de desvios a partir do mesmo, o que permite que os ganhos e as perdas possam ser interpretados de maneiras diversas. Nesse aspecto, o ponto de referência pode ser interpretado como o ponto onde $\mathrm{x}=0$ e a forma da função de valor seria côncava para ganhos e convexa para perdas, sendo que a inclinação seria mais íngreme para as perdas, o que implica que as escolhas são mais inconsistentes (Falleiro, 2014). A Figura 1 ilustra a função de valor da Teoria do Prospecto. 


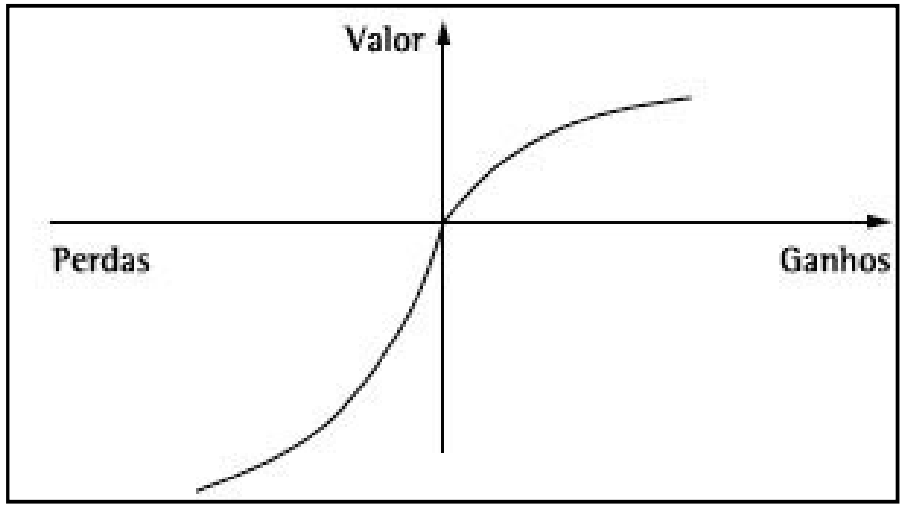

Fonte: Kahneman e Tversky (1979), adaptado pelos autores.

Figura 1. Função Hipotética de Valor da Teoria do Prospecto

O principal conceito que as Finanças Comportamentais abordam é o de "aversão às perdas". Este conceito diz que as pessoas não têm aversão ao risco e sim à perda. As pessoas preferem não sofrer a dor da perda do que o prazer de um ganho equivalente, ou seja, é preferível não perder $\mathrm{R} \$ 100,00 \mathrm{a}$ ganhar $\mathrm{R} \$ 100,00$. Também assumem riscos quando estão perdendo, mas são totalmente avessos ao risco quando estão ganhando (Araújo e Silva, 2007, p. 49).

Neste sentido, Lobo et al., (2011) corroboram que as finanças comportamentais dão destaque à aversão à perda em contraposição aos conceitos econômicos que sustentam que os investidores devem arriscar enquanto ganham e devem ser contrários ao risco quando perdem. De acordo com os mesmos, a aversão à perda é um dos mais importantes conceitos trabalhados pelas Finanças Comportamentais entre distintas anomalias testadas e estudadas por pesquisadores desta área. De acordo com a Comissão de Valores Mobiliários [CVM] (2015) este viés também acaba induzindo os indivíduos a correr riscos com uma maior frequência na tentativa de reparar ocasionais prejuízos.

\section{Excesso de confiança}

0 viés excesso de confiança, induz o indivíduoa confiar de forma excessiva em suas próprias opiniões e conhecimentos, além de maximizar sua contribuição individual para a tomada de decisão, possuindo a tendência de acreditar que está sempre correto em suas escolhas e incumbindo a fatores externos os seus eventuais erros. Em outras palavras, os indivíduos se identificam como melhores que a média geral, sendo esse viés também conhecido como overconfidence (Zindel, 2008; Mendes-daSilva \& Yu, 2009; Nofsinger, 2010; Moreira, 2012).

Este viés decorre da crença dos indivíduos de que a informação em seu poder é suficiente para o processo decisório, que são mais capazes de controlar os seus eventos do que são na realidade, ou ainda que tem uma capacidade maior do que os demais agentes do mercado (CVM, 2015).

[...] este viés faz com que os investidores acreditem que suas informações são melhores e mais confiáveis que as dos demais indivíduos atuantes no mesmo mercado. Geralmente, em uma negociação, as partes envolvidas possuem informações diferentes, possivelmente contraditórias. Sabendo disso, os agentes participantes de uma negociação deveriam refletir mais e apenas tomar decisões quando estivessem certos da confiabilidade das informações que recebem; porém, a confiança excessiva em suas habilidades e informações faz com que eles tendam a realizar um volume de negócios excessivos, arriscando mais do que o previsto (Pimenta, Borsato \& Ribeiro, 2012, p. 267).

Ferreira e Yu (2003) reiteram que o excesso de confiança é originado de distintos erros cognitivos cometidos pelos indivíduos no processo de tomada de decisão, no qual estes erros fazem com que os indivíduos avaliem de forma irreal as situações de tomada de decisão.

\section{GÊNERO}

As discussões teóricas a respeito do gênero e possíveis diferenças estão presentes em 
diversas áreas, e continuam gerando muitos debates. Em contextos que envolvem termos como sexo, gênero, homens, mulheres, masculinidade e feminilidade, a discussão central concentra-se na afirmação da masculinidade hegemônica. Justifica-se pelo controle masculino estabelecido, tendo como fio condutor a racionalidade instrumental.

Conforme Fournier e Smith (2006) a análise essencialista trata o gênero de forma dominante, gerando problemas nas discussões de identidades múltiplas, que na essência, são únicas ou masculinizadas. A mulher é vista então como um estado de natureza. Está basicamente vinculada as funções de reprodução, sexualidade e família. Contrapondo-se a essa hegemonia da masculinidade, as transformações nos papéis sociais têm aproximado as mulheres do mundo do trabalho.

Sendo assim, a intenção desta pesquisa é explorar o gênero no âmbito da tomada de decisão, investigando os vieses comportamentais. As oportunidades de pesquisa em finanças comportamentais, se referem a investigação de como o gênero afeta os investimentos, seja por meio do estilo pessoal e/ou alocação de ativos (Filbeck et al., 2017). Analisando a função de valor para caracterizar os indivíduos em relação ao risco, Malul, Rosenboim e Shavit (2013) verificaram que existem diferenças entre os indivíduos, sendo necessário uma análise mais aprofundada para caracterizá-los. Em suma, existem diferentes funções de valores para grupos distintos de indivíduos. Nesse sentido, a variável gênero pode ser um elemento relevante para investigações futuras e entendimento das distintas funções de valor.

Para corroborar a importância da análise do gênero, salienta-se a aplicação da variável em outras temáticas comportamentais. Como exemplo, Flores e Vieira (2016), que buscaram analisar a influência do gênero nas determinantes (percepção de risco, comportamento de risco, emoções, materialismo e valores do dinheiro) do endividamento no município de Santa Maria Rio Grande do Sul. Como resultado, os autores constataram que os homens apresentaram maiores coeficientes e acabam sofrendo maior influência das emoções, comportamento de risco e valores do dinheiro. Quanto às mulheres, a única evidência encontrada que caracteriza um comportamento distinto diz respeito ao endividamento e as emoções negativas, uma vez que apresentam uma maior disposição em explicar os sentimentos frente a um cenário de dívidas.

No que se refere a influência do gênero nos vieses comportamentais, Croson e Gneezy (2009) efetuaram uma pesquisa sobre o gênero e as preferências por risco. Os autores expuseram que as mulheres são mais avessas ao risco e optam por situações menos competitivas que os homens, o que pode explicar questões mais amplas, como as diferenças salariais entre ambos. Gava e Vieira (2008) também analisaram essa temática, buscando desenvolver um instrumento de pesquisa para classificação dos investidores quanto à tolerância ao risco. Confirmaram que os homens são mais propensos ao risco que as mulheres.

Yang e Zhu (2016) investigaram o efeito do excesso de confiança e do gênero na atividade de negociação em mercados de ativos sob uma configuração de informação simétrica.Os autores desenvolveram experimentos, identificando que os homens possuem um maior excesso de confiança que as mulheres.Complementando, foi feito um breve levantamento acerca dos estudos realizados em âmbito nacional e internacional, cujos resultados estão expostos no Quadro 1.

Tendo em vista o referencial teórico deste trabalho, a seguir será abordado o método de pesquisa do mesmo.

\section{MÉTODO}

Visando atender ao objetivo proposto, esta pesquisa possui caráter descritivo e abordagem quantitativa. Gil (2010, p. 27) afirma que "as pesquisas descritivas têm como objetivo a descrição de características de uma determinada população. Podem ser elaboradas também com a finalidade de identificar possíveis relações entre variáveis". A abordagem da pesquisa é de caráter quantitativo, pois, na visão de Marconi e Lakatos (2011, p. 290) "é a mais apropriada para apurar atitudes e responsabilidades dos entrevistados, uma vez que emprega questionários e deve representar um determinado universo, para que seus dados 
possam ser generalizados e projetados para aquele ambiente".

0 método utilizado foi a pesquisa survey, pois, de acordo com Lima (2008, p. 30) em uma survey descritiva "a investigação se compromete a identificar quais situações, eventos, atitudes ou opiniões estão manifestos em determinada população, ou descrever a distribuição de algum fenômeno ocorrido com tal grupo, tendo como referência uma amostra representativa da população".

\begin{tabular}{|c|c|c|}
\hline Viés & Relação com gênero & Referências \\
\hline \multirow[t]{2}{*}{ Excesso de confiança } & Homens mais confiantes & $\begin{array}{l}\text { Johnson e } \\
\text { (1994);Ferreira e Yu (2003); } \\
\text { Lucena, Fernandes e Silva } \\
\text { (2011); Yang e Zhu (2016). }\end{array}$ \\
\hline & Não há diferença & Bogea e Barros (2008); \\
\hline \multirow[t]{3}{*}{ Aversão a perda } & Mulheres mais avessas & $\begin{array}{l}\text { Zuckerman e Kuhlman, (2000); } \\
\text { Croson e Gneezy (2009); Araújo } \\
\text { e Silva (2007); Gava e Vieira } \\
\text { (2008);Flores e Vieira (2016); }\end{array}$ \\
\hline & Homens mais avessos & $\begin{array}{l}\text { Chapple e Johnson (2007); } \\
\text { Cotrim (2014). }\end{array}$ \\
\hline & Não há diferença & Melo e Silva (2010); \\
\hline
\end{tabular}

Fonte: Elaborado pelos autores.

Quadro 1. Vieses e Relação com o gênero

0 instrumento de coleta de dados utilizado foi o questionário, que de acordo com Gil (2008) é definido como a técnica de investigação constituída por um grupo de questões que são submetidas a pessoas com o objetivo de coletar dados sobre valores, comportamentos, conhecimentos, etc. 0 questionário utilizado nesta pesquisa foi construído com base em Scheir e Carver (1992), Bandeira (2002) e Melo (2014), sendo efetuadas adaptações às características da amostra. 0 instrumento é composto por seis questões de múltipla escolha (perfil) e também por oito questões em escala tipo Likert (aversão a perda e excesso de confiança).

Para a validação do questionário foi realizado um pré-teste, conforme recomendações de Hair Jr. et al. (2005). O tamanho da amostra de um pré-teste ainda de acordo com o autor deve ser no mínimo quatro ou cinco indivíduos e não ultrapassar a trinta.Com isso, o mesmo foi realizado com 8 estudantes do Curso de Gestão Pública da Universidade Federal do Pampa, e para o melhor entendimento de algumas questões foram feitas algumas adaptações, sem exclusão de variáveis.

A população desta pesquisa compreende os estudantes do Curso de Administração de uma
Universidade do Rio Grande do Sul, que somam 423 estudantes de acordo com dados da Secretaria Acadêmica (2015). Devido a amplitude da população, utilizou-se o processo de amostragem Gil (2008, p. 90) que "é um subconjunto do universo ou da população, por meio do qual se estabelecem ou se estimam as características desse universo ou população". Deste modo, escolheu-se por utilizar nesta pesquisa uma amostragem de cunho probabilístico (estatístico), uma vez que se pode generalizar os resultados atingidos. No que diz respeito a técnica de amostragem probabilística, optou-se pela amostragem aleatória simples que na visão Hair Jr. et al., (2005 p. 240) "é um método direto de amostragem que atribui a cada elemento da população alvo uma igual probabilidade de ser selecionado".

A amostra foi calculada com um nível de confiança de $95 \%$ e tolerou-se um erro amostral de $10 \%$, para uma população finita de 423 estudantes. Em vista disso, obteve-se como resultado uma amostra de 81 estudantes. Visando manter a aleatoriedade da pesquisa, foram realizados quatro sorteios aleatórios no Microsoft Excel, a partir dos dados concedidos pela Secretaria Acadêmica da referida instituição (2015), como os nomes e e-mails de todos os acadêmicos matriculados no curso de 
Administração, solicitados através de uma carta de apresentação. A coleta de dados ocorreu durante os meses de março e abril de2016.

Os dados foram mensurados de forma quantitativa utilizando-se de procedimentos estatísticos, onde os resultados foram calculados eletronicamente por meio do software SPSS 20.0 e foram analisadas através da estatística descritiva (média, desvio padrão, frequência, percentual). E, para analisar os vieses conforme o gênero, primeiramente realizou-se o teste de Kolmogorov-Smirnov (KS) de uma amostra, com a finalidade de definir a melhor distribuição amostral. De acordo com Castellan e Siegel (2006, p. 70), esse teste [...] "admite que a distribuição da variável subjacente que está sendo testada é contínua, como especificada pela distribuição de frequências acumuladas. Assim, o teste é apropriado para testar a aderência para variáveis que são medidas pelo menos em uma escala ordinal". A seguir são citadas as hipóteses deste trabalho em relação ao gênero para cada questão:

H0: Não há diferença nos vieses conforme o gênero.
H1: Existe diferença nos vieses conforme o gênero.

Após a realização do teste KS, conclui-se que a pesquisa deve utilizar estatísticas nãoparamétricas, através da mediana, sendo indicado para amostras menores. Neste sentido, adotou-se o teste Wilcoxon-Mann-Whitney que de acordo comCastellan e Siegel (2006, p. 153) [...] "pode ser usado para testar se dois grupos independentes foram extraídos de uma mesma população".

\section{ANÁLISE E DISCUSSÃO DOS RESULTADOS}

Está seção está dividida em três partes, a primeira refere-se à caracterização do perfil da amostra, a segunda aborda os resultados acerca da aversão a perda e excesso de confiança e por fim tem-se a análise dos vieses conforme o gênero.

\section{Perfil dos respondentes}

O questionário foi aplicado a 81 estudantes, sendo estes com uma idade em média de 25 anos, sendo que os demais resultados acerca do perfil estão expostos na Tabela 1.

\section{Tabela 1}

Perfil dos respondentes através das variáveis: gênero e estado civil, ocupação e renda

\begin{tabular}{|c|c|c|c|}
\hline Variável & Alternativas & Frequência & Percentual válido \\
\hline \multirow{2}{*}{ Gênero } & Feminino & 46 & 57,5 \\
\hline & Masculino & 34 & 42,5 \\
\hline \multirow{2}{*}{ Estado Civil } & Solteiro (a) & 63 & 79,7 \\
\hline & Casado (a) /União estável & 16 & 20,3 \\
\hline \multirow{2}{*}{$\begin{array}{c}\text { Você exerce } \\
\text { atividade } \\
\text { remunerada? }\end{array}$} & Não & 21 & 25,9 \\
\hline & Sim & 60 & 74,1 \\
\hline \multirow{7}{*}{$\begin{array}{c}\text { Assinale a sua } \\
\text { renda } \\
\text { individual } \\
\text { mensal (pode } \\
\text { ser } \\
\text { aproximada): }\end{array}$} & Não possuo renda individual & 17 & 21,5 \\
\hline & Até $\mathrm{R} \$ 500,00$ & 9 & 11,4 \\
\hline & $\begin{array}{l}\text { Entre } \mathrm{R} \$ 500,00 \text { e } \mathrm{R} \$ \\
1.000,00\end{array}$ & 24 & 30,4 \\
\hline & $\begin{array}{l}\text { Entre } \mathrm{R} \$ 1.000,00 \text { e } \mathrm{R} \$ \\
1.500,00\end{array}$ & 10 & 12,7 \\
\hline & $\begin{array}{l}\text { Entre } R \$ 1.500,00 \text { e } R \$ \\
2.500,00\end{array}$ & 11 & 13,9 \\
\hline & $\begin{array}{l}\text { Entre } \mathrm{R} \$ 2.500,00 \text { e } \mathrm{R} \$ \\
3.500,00\end{array}$ & 4 & 5,1 \\
\hline & Mais de $\mathrm{R} \$ 3.500,00$ & 4 & 5,1 \\
\hline
\end{tabular}

Fonte: Dados da pesquisa (2016). 
No que se refere ao gênero, percebe-se através da Tabela 1 que a maioria dos respondentes $(57,5 \%)$ pertencem ao gênero feminino, quanto ao estado civil, são solteiros $(79,7 \%)$. Referente a ocupação, a maior parte exerce algum tipo de atividade remunerada $(74,1 \%)$. Na sequência, perguntou-se o tipo de atividade remunerada que os estudantes exercem e a mais citada foi o estágio remunerado e entre as atividades estão, auxiliar de escritório, auxiliar administrativo, auxiliar contábil, entre outros. Com relação a renda, a maioria dos respondentes possui renda individual mensal entre $\mathrm{R} \$ 500,00$ e $\mathrm{R} \$ 1.000,00$
$(30,4 \%)$. E, por fim, foi questionado o semestre, identificando-se que grande parte está no $6^{\circ}$ semestre $(25,9 \%)$.

\section{Aversão a perda e excesso de confiança}

Após a descrição do perfil da amostra, serão analisados os vieses aversão a perda e excesso de confiança. 0 primeiro viés analisado será a aversão a perda, cujos resultados encontram-se na Tabela 2. Cabe ressaltar que nestas questões um menor grau de concordância indicaria a presença do viés.

Tabela 2

Resultados Aversão a Perda

\begin{tabular}{c|l|c|c|c|c|c}
\hline \multicolumn{1}{|c|}{ Afirmativas } & DT & D & I & C & CT \\
\hline $\mathbf{1}$ & $\begin{array}{l}\text { Ao achar } \mathrm{R} \$ 0,50 \text { o prazer que eu sinto é maior } \\
\text { que a dor que tenho por perder } \mathrm{R} \text { 0,50. }\end{array}$ & $7,4 \%$ & $11,1 \%$ & $25,9 \%$ & $\mathbf{3 4 , 6 \%}$ & $21 \%$ \\
\hline $\mathbf{2}$ & $\begin{array}{l}\text { O prazer que eu sentiria por ganhar } \mathrm{R} \$ \\
4.000 .000,00 \text { seria similar à dor por perder } \\
\mathrm{R} \$ 4.000 .000,00 .\end{array}$ & $\mathbf{3 0 , 9 \%}$ & $28,4 \%$ & $11,1 \%$ & $18,5 \%$ & $11,1 \%$ \\
\hline $\mathbf{3}$ & $\begin{array}{l}\text { O prazer que eu sentiria por ganhar } \mathrm{R} \$ \\
3.000 .000,00 \text { seria similar à dor por perder } \\
\mathrm{R} \$ 3.000 .000,00 .\end{array}$ & $\mathbf{3 0 , 9 \%}$ & $27,2 \%$ & $9,9 \%$ & $19,8 \%$ & $8,3 \%$ \\
\hline $\mathbf{4}$ & $\begin{array}{l}\text { Ao achar } \mathrm{R} \$ 1,00 \text { o prazer que eu sinto é maior } \\
\text { que a dor que tenho por perder } \mathrm{R} \$ 1,00 .\end{array}$ & $9,9 \%$ & $13,6 \%$ & $27,2 \%$ & $\mathbf{3 5 , 8 \%}$ & $13,6 \%$ \\
\hline
\end{tabular}

Fonte: Dados da pesquisa (2016).

Nota. Discordo total (DT), Discordo (D), Indiferente (I), Concordo (C) e Concordo totalmente (CT).

Percebe-se através da Tabela 2, que na questão 1 a maioria dos respondentes $(34,6 \%)$ concordam que ao achar $\mathrm{R} \$ 0,50$ o prazer que sentem é maior do que a dor da perda do mesmo valor, o que ocorre também na questão 1.7, na qual $35,8 \%$ dos respondentes também concordam que o prazer que sentem ao achar $\mathrm{R} \$ 1,00$ é maior do que a dor que sentem por perder $\mathrm{R} \$ 1,00$. Estes resultados não corroboram os estudos de Kahneman e Tversky (1979), onde os autores sustentam que as pessoas sentem muito mais a dor da perda do que o prazer obtido por um ganho semelhante.

Neste sentido, através destas questões os estudantes de Administração não demonstraram a presença do viés da aversão à perda, o que pode acontecer devido ao baixo valor monetário envolvido nas mesmas. Já, nas questões 1.3 e 1.5 , em que o valor monetário envolvido é muito alto, a maioria dos respondentes $(30,9 \%)$ em ambas as questões discordaram totalmente que o prazer do ganho seria similar à dor da perda, o que está de acordo com os estudos de Kahneman e Tversky (1979), Araújo e Silva (2007) e Lobo et al. (2011).

A Tabela 3 expõe os resultados do viés excesso de confiança, onde nas questões 5, 6 e 7 um maior grau de concordância é que indicaria a presença do viés, e na questão 8,um menor grau de concordância é que indicaria a presença do viés.

Tabela 3

Resultados Excesso de Confiança

\begin{tabular}{c|l|c|c|c|c|c}
\hline \multicolumn{1}{|c|}{ Afirmativas } & DT & D & I & C & CT \\
\hline $\mathbf{5}$ & $\begin{array}{l}\text { Eu sou sempre otimista com relação ao meu } \\
\text { futuro. }\end{array}$ & 0 & $12,5 \%$ & $5 \%$ & $\mathbf{5 0 \%}$ & $32,5 \%$ \\
\hline $\mathbf{6}$ & Nos momentos de incerteza, eu geralmente & $1,2 \%$ & $9,9 \%$ & $11,1 \%$ & $\mathbf{4 5 , 7 \%}$ & $32,1 \%$ \\
\hline
\end{tabular}




\begin{tabular}{c|l|c|c|c|c|c}
\hline & espero que aconteça o melhor. & & & & \\
\hline $\mathbf{7}$ & $\begin{array}{l}\text { De maneira geral, eu espero que aconteçam } \\
\text { mais coisas boas do que coisas ruins. }\end{array}$ & 0 & $2,5 \%$ & $3,7 \%$ & $40,7 \%$ & $\mathbf{5 3 , 1 \%}$ \\
\hline $\mathbf{8}$ & $\begin{array}{l}\text { Se alguma coisa ruim pode acontecer comigo, } \\
\text { vai acontecer. }\end{array}$ & $18,8 \%$ & $\mathbf{4 0 \%}$ & $20 \%$ & $15 \%$ & $6,3 \%$ \\
\hline
\end{tabular}

Fonte: Dados da pesquisa (2016).

Nota. Discordo total (DT), Discordo (D), Indiferente (I), Concordo (C) e Concordo totalmente (CT).

Através da Tabela 3 observa-se que na questão 5, 50\% dos respondentes concordam que são sempre otimistas em relação ao futuro, o que representa uma forte presença do viés excesso de confiança nos mesmos. Esse fato que se confirma através da questão 7 , onde $53,1 \%$ dos respondentes concordam totalmente que esperam que aconteça com eles mais coisas boas do que coisas ruins e na questão 8 , onde a maioria dos respondentes (40\%) discordam que se alguma coisa ruim pode acontecer com

\section{Análise dos vieses conforme o gênero}

Este trabalho apresenta a análise do gênero com a alternativa escolhida pelos estudantes. eles, vai acontecer. Caracteriza-se a presença do viés, o que pode prejudicar o processo de tomada de decisão financeira, já que pressupõe uma visão otimista dos cenários. Esses resultados corroboram com os autores Ferreira e Yu (2003) e Pimenta et al. (2012).

Na questão 6 percebe-se que a maioria dos respondentes $(45,7 \%)$ concordam que nos momentos de incerteza, geralmente esperam que aconteça o melhor, um dado que também indica a presença do viés nos respondentes. Esta análise está dividida em duas partes, a primeira contém o cruzamento entre o gênero e as questões de 1 a 4 , cujos resultados estão expostos na Tabela 4.

Tabela 4

Aversão a perda e gênero

\begin{tabular}{|c|c|c|}
\hline & Questões & Significância \\
\hline 1 & Ao achar R\$ 0,50 o prazer que eu sinto é maior que a dor que tenho por perder $\mathrm{R} \$ 0,50$. & 0,394 \\
\hline 2 & $\begin{array}{l}\text { O prazer que eu sentiria por ganhar } \mathrm{R} \$ 4.000 .000,00 \text { seria similar à dor por perder } \\
\mathrm{R} \$ 4.000 .000,00 \text {. }\end{array}$ & 0,407 \\
\hline 3 & $\begin{array}{l}\text { O prazer que eu sentiria por ganhar } \mathrm{R} \$ 3.000 .000,00 \text { seria similar à dor por perder } \\
\mathrm{R} \$ 3.000 .000,00 \text {. }\end{array}$ & 0,632 \\
\hline 4 & Ao achar $\mathrm{R} \$ 1,00$ o prazer que eu sinto é maior que a dor que tenho por perder $\mathrm{R} \$ 1,00$. & 0,485 \\
\hline
\end{tabular}

Fonte: Dados da pesquisa (2016).

Percebe-se, através da Tabela 4, que todas as questões apresentam significância maior que 0,05 . Desta forma, conclui-se pela aceitação da H0 e a rejeição da H1. O que significa dizer que os estudantes do Curso de Administração da Universidade não apresentaram diferença nos vieses conforme o gênero, corroborando assim com o estudo de Melo e Silva (2010). Assim, pode-se notar que a tomada de decisão foi semelhante entre os estudantes de ambos os gêneros. Os resultados podem ser atribuídos a homogeneidade da amostra e diferenciam-se de outros achados na literatura (Zuckerman e Kuhlman, 2000; Araújo \& Silva, 2007; Chapple \& Johnson, 2007; Cotrim, 2014; Flores \& Vieira, 2016). A Tabela 5 apresenta os resultados relacionados ao excesso de confiança.

\section{Tabela 5}

Excesso de confiança e gênero

\begin{tabular}{c|l|c}
\hline & \multicolumn{1}{c}{ Questões } & Significância \\
\hline $\mathbf{5}$ & Eu sou sempre otimista com relação ao meu futuro. & 0,956 \\
\hline $\mathbf{6}$ & Nos momentos de incerteza, eu geralmente espero que aconteça o melhor. & 0,281 \\
\hline $\mathbf{7}$ & De maneira geral, eu espero que aconteçam mais coisas boas do que coisas ruins. & 0,189 \\
\hline $\mathbf{8}$ & Se alguma coisa ruim pode acontecer comigo, vai acontecer. & 0,828 \\
\hline
\end{tabular}

Fonte: Dados da pesquisa (2016). 
Através da Tabela 5 é possível observar que em todas questões relacionadas ao excesso de confiança a significância também foi maior que 0,05. Concluindo-se também a aceitação da H0e a rejeição da $\mathrm{H} 1$, não existindo diferença no excesso de confiança conforme o gênero, corroborando com o estudo de Bogea e Barros (2008), onde os autores o buscaram relacionar o excesso de confiança com características dos participantes, como gênero, porém, as análises estatísticas não apresentaram relações consideráveis.

Portanto, foi possível perceber que os estudantes não apresentaram diferença conforme o gênero em nenhum dos vieses analisados. Este resultado pode ter ocorrido devido ao tamanho da amostra ser pequeno, ou até mesmo pelo fato da população escolhida, uma vez que os estudantes podem possuir características semelhantes. Sendo assim, conclui-se a pesquisa apresentando as considerações finais.

\section{CONSIDERAÇÕES FINAIS}

Assim como nos estudos de Kahneman e Tversky (1979), os resultados da pesquisa mostraram que os respondentes são avessos ao risco no domínio dos ganhos e propensos ao risco no domínio das perdas, estando este comportamento atrelado ao valor monetário da operação. Referente ao excesso de confiança percebeu-se a presença do mesmo, pois os respondentes costumam julgar situações arriscadas sob perspectivas otimistas. Em relação a análise dos vieses conforme o gênero, constatou-se que não houve diferença. 0 que pode estar atrelado ao tamanho da amostra, bem como as possíveis semelhanças nas características da população escolhida. De forma geral, a aversão a perda e o excesso de confiança influenciaram a decisão dos estudantes, sendo relevante uma reflexão sobre o tema já que erros cognitivos causam uma decisão equivocada, que em âmbito organizacional pode ser prejudicial.

A principal contribuição do trabalho está no fornecimento de novas evidências sobre vieses comportamentais em estudantes, utilizando como referência, o comparativo entre gênero. Em termos teóricos, a pesquisa demonstra um perfil de estudantes do Curso de Administração, sendo interessante realizar outras investigações em diferentes áreas do conhecimento. Em termos práticos, o estudo poderá ser utilizado para o desenvolvimento de ações, que busquem auxiliar na tomada de decisão dos estudantes e considerar a influência dos aspectos comportamentais. Assim, as universidades, por exemplo, poderão investir na criação de um currículo que permita ao estudante aprofundarse nessas questões, visto que as mesmas podem ter relação com o desempenho acadêmico (Soares \& Barbedo, 2013).

Conjecturando que tais atividades podem impactar em questões pessoais e profissionais, a pesquisa é mais um resultado da importância das finanças comportamentais no nosso dia-adia. Além desses aspectos, verificou-se que nesta amostra não houver diferença entre os gêneros, sendo necessário continuar investigando as contribuições dessa variável no processo decisório.

Quanto às limitações, a principal delas se refere ao universo do trabalho, pois não permite generalização. A escolha das variáveis (vieses) assim como análise do gênero também representa uma limitação, uma vez que, na literatura acerca de Finanças Comportamentais são abordados inúmeros vieses comportamentais e outras variáveis poderão exercer influência no comportamento. Sendo assim, este estudo acabou contribuindo para um melhor entendimento do comportamento financeiro dos indivíduos. Sugere-se que estudos futuros investiguem as diferenças através de outras variáveis sóciodemográficas, a fim de encontrar características específicas dos indivíduos, com base em estudos qualitativos e quantitativos.

\section{REFERÊNCIAS}

Araújo, D. R. D., \& Silva, C. A. T. (2007). Aversão à perda nas decisões de risco. REPEC-Revista de Educação e Pesquisa em Contabilidade, 1(3), 45-62.

Bandeira, et al. (2002). Validação transcultural do Teste de Orientação da Vida (TOV-R). Estudos de Psicologia, 7(2), 251-258.

Bogea, F., de Campos Barros, L. A. B., \& de Campos Barros, A. B. (2008). Processo de tomada de decisão do investidor individual brasileiro no mercado acionário nacional: um estudo exploratório enfocando o efeito disposição e 
os vieses da ancoragem e do excesso de confiança. Gestão \& Regionalidade, 24(71).

Castellan, J. N.,Jr, \& Siegel, S. (2006). Estatística nãoparamétrica para ciências do comportamento. Porto Alegre: Artmed.

Chapple, C. L., \& Johnson, K. A. (2007). Gender differences in impulsivity. Youth Violence and Juvenile Justice, 5(3), 221-234.

Comissão de Valores Mobiliários. (2015). Série CVM Comportamental: Volume 1 Vieses do Investidor. Recuperado em 10 outubro, de 2016,

de

<www.portaldoinvestidor.gov.br/portaldoinv estidor/export/sites/portaldoinvestidor/publ icacao/Serie-

CVMComportamental/CVMComportamentalVol1-ViesesInvestidor.pdf>.

Cotrim, B.S. (2014). Vieses cognitivos e o investidor individual brasileiro: uma análise da intensidade de vieses em decisões de investidores. Dissertação (Mestrado em Ciências) - Programa de Pós-graduação em Controladoria e Contabilidade da Universidade de São Paulo. São Paulo: USP, 2014.

Croson, R., \& Gneezy, U. (2009). Gender differences in preferences. Journal of Economic literature, 47(2), 448-74.

Falleiro, M. P. D. S. (2014). Teoria do prospecto e as diferenças de comportamento perante o risco entre gênero, escolaridade e idade. (Master's thesis, Pontifícia Universidade Católica do Rio Grande do Sul).

Ferreira, C. F., Yu, A. S. O., Sá, G., de Oliveira, G. A., de Oliveira Siqueira, J., Zimmer, C. J., \& dos Santos, A. (2003). Todos acima da média: excesso de confiança em profissionais de finanças. Revista de Administração, São Paulo, 38(2), 101-111.

Filbeck, G., Ricciardi, V., Evensky, H. R., Fan, S. Z., Holzhauer, H. M., \& Spieler, A. (2017). Behavioral finance: A panel discussion. Journal of Behavioral and Experimental Finance, 15, 52-58.

Flores, S. A. M., \& Vieira, K. M. (2016). Determinantes comportamentais da propensão ao endividamento: Análise da influência do gênero. Anais do Encontro Brasileiro de Economia e Finanças Comportamentais da $F G V$, São Paulo, SP, Brasil, 3.

Fournier, V., \& Smith, W. (2006). Scripting masculinity. Ephemera, 141.

Gava, A. M, \& Vieira, K. M. (2008). Risco e gênero: Medindo a tolerância ao risco e as diferenças entre os gêneros. Revista de Ciências da Administração, 10(20).
Gil, A. C. (2008). Métodos e técnicas de pesquisa social. São Paulo: Atlas.

GIL, A. C. (2010). Como elaborar projetos de pesquisa. São Paulo: Atlas.

Hair, J., et al., (2005). Fundamentos de métodos de pesquisa em administração. Bookman Companhia Ed.

Johnson, J. E., \& Powell, P. L. (1994). Decision making, risk and gender: Are managers different?. British Journal of Management, 5(2), 123-138.

Kahneman, D. (2012). Rápido e devagar: duas formas de pensar. Editora Objetiva.

Kahneman, D., \& Tversky, A. (1979). Prospect Theory: An analysis of decision under risk. Econometrica: Journal of the Econometric Society, 263-291.

Keese, M. (2010). Who feels constrained by high debt burdens? Subjective vs. objective measures of household indebtedness. Subjective vs. Objective Measures of Household Indebtedness (February 1, 2010). Ruhr Economic Paper, (169).

Kimura, H. (2003). Aspectos comportamentais associados às reações do mercado de capitais. RAE-eletrônica, 2(1), 1-14.

Lima, M. C. (2008). Monografia: a engenharia da produção acadêmica. São Paulo: Saraiva, 2008.

Lobão, J. (2012). Finanças comportamentais: Quando a economia encontra a psicologia. Coimbra: Conjuntura Actual Editora.

Lobo, B. G, et al. (2011). A influência do viés aversão à perda e do significado do dinheiro sobre o processo decisório de empreendedores brasileiros. In: Seminários em Administração, 14., 2011, São Paulo. Anais eletrônicos... São Paulo: SEMEAD, 2011.

Lucena, W. G. L., Fernandes, M. S. A., \& da Silva, J. D. G. (2011). A contabilidade comportamental e os efeitos cognitivos no processo decisório: uma amostra com operadores da contabilidade. Revista Universo Contábil, 7(3), 41-58.

Macedo Junior, J. S., Jr., Kolinsky, R., \& Morais, J. (2011). Finanças comportamentais: Como o desejo, o poder, o dinheiro $e$ as pessoas influenciam nossas decisões. São Paulo: Atlas.

Macedo, J. S., Jr. (2003). Teoria do prospecto: uma investigação utilizando simulação de investimentos. Programa de Pós-Graduaçao em Engenharia de Produçao, Universidade de Santa Catarina.

Malul, M., Rosenboim, M., \& Shavit, T. (2013). So when are you loss averse? Testing the S-shaped function in pricing and allocation tasks. Journal of Economic Psychology, 39, 101-112.

Marconi, M. de A., \& Lakatos, E. M. (2011). Metodologia científica. São Paulo: Atlas. 
Martins, G. D. A., \& Theóphilo, C. R. (2009). Metodologia da investigação cientifica. São Paulo: Atlas.

Melo, C. L. L. D. (2014). Determinantes da aversão à perda em decisões financeiras: uma investigação por meio de modelos de equações estruturais. Tese (Doutorado em Ciências Contábeis) - Programa Multi-institucional e Inter-Regional de Pós-Graduação em Ciências Contábeis, Universidade de Brasília.

Melo, C. L. L., \& Silva, C. A. T. (2010). Finanças Comportamentais: um estudo da influência da faixa etária, gênero e ocupação na aversão à perda. $R C O$ - Revista de Contabilidade $e$ Organizações - FEA-RP/USP, 4(8), 3-23.

Mendes-da-Silva, W., \& Sin Oih Yu, A. (2009). Análise empírica do senso de controle: buscando entender o excesso de confiança. RAC-Revista de Administração Contemporânea, 13(2).

Moreira, B. C. D. M. (2012). Três ensaios sobre finanças comportamentais e neuroeconomia: testando o efeito dotação, efeito overconfidence $e$ efeito gratificação instantânea em crianças. Tese (doutorado) - Universidade Federal de Santa Catarina, Centro Sócio-Econômico. Programa de Pós-Graduação em Administração.

Nofsinger, J.R. (2010). A lógica do mercado de ações. $2^{a}$ ed. São Paulo: Fundamento, 2010.

Pimenta, D. P., Borsato, J. M. L. S., \& de Sousa Ribeiro, K. C. (2012). Um estudo sobre a influência das características sociodemográficas e do excesso de confiança nas decisões dos investidores, analistas e profissionais de investimento à luz das Finanças Comportamentais. REGE-Revista de Gestão, 19(2), 263-280.

Pompian, M. M. (2006). Behavioral finance and wealth management. How to build optimal portfolios for private clients. New Jersey: Wiley.

Ramos, A. L. (2007). Análise do efeito comportamental do índice ibovespa: um estudo interdisciplinar. 2007. 126f (Dissertação de Mestrado) Mestrado em Ciências Contábeis-
Curso de Pós-graduação em Ciências Contábeis, Pontifícia Universidade Católica de São Paulo, São Paulo).

Santos, J. O. dos; Barros, C. A. S. (2011). O que determina a tomada de decisão financeira: razão ou emoção? Revista Brasileira de Gestão e Negócios. São Paulo, 13(38), 7-20.

Scheier, M. F, \& Carver, C. S. (1992). Effects of optimism on psychological and physical wellbeing: theoretical overview and empirical update. Cognitive Therapy and Research, 16(2), 201-228.

Silva, W. V., Del Corso, J. M., da Silva, S. M., \& de Oliveira, E. (2009). Finanças comportamentais: análise do perfil comportamental do investidor e do propenso investidor. Revista Eletrônica de Ciência Administrativa, 7(2), 1-14.

Silva, W. M. da, Yu, A. S. O. Análise Empírica do Senso Controle: Buscando Entender o Excesso de Confiança. Revista de Administração Contemporânea, 13(2), 247-271.

Soares, H. F.G, \& Barbedo, C. H.S. (2013). Desempenho acadêmico e a teoria do prospecto: estudo empírico sobre o comportamento decisório. Revista de Administração Contemporânea, 17(1).

Statman, M. (2014). Behavioral finance: Finance with normal people. Borsa Istanbul Review, 14(2), 65-73.

Yang, X., \& Zhu, L. (2016). Ambiguity vs risk: An experimental study of overconfidence, gender and trading activity. Journal of Behavioral and Experimental Finance, 9, 125-131.

Zindel, M. T. L. (2008). Finanças comportamentais: o viés cognitivo excesso de confiança no julgamento em investidores e sua relação com bases biológicas. Tese (doutorado) Universidade Federal de Santa Catarina, Centro Tecnológico. Programa de PósGraduação em Engenharia de Produção.

Zuckerman, M., \& Kuhlman, D. M. (2000). Personality and risk-taking: common bisocial factors. Journal of personality, 68(6), 999-1029.

\title{
Aversion to loss and overconfidence under the perspective of gender
}

\begin{abstract}
Financial decision making is one of the aspects studied by Behavioral Finances, starting from the assumption of the limited rationality of individuals. Specifically considering the students, one can understand the validity of the judgments made, being an aid in their professional performance. Thus, the present study sought to analyze the behavioral biases of loss aversion and overconfidence in students of the Administration Course of a University of Rio Grande do Sul from the perspective of the gender. The
\end{abstract}


first bias causes individuals to take more frequent risks in their decisions, while the second one makes them trust more than they should in their own knowledge and opinions. A survey was carried out comprising 81 respondents, from a structured questionnaire, which addressed behavioral biases and profile questions. Through the analysis it was possible to observe that the students have the biases analyzed and that these affect the decision making. From the perspective of the gender, it has been realized that there is no difference.

Keywords: Loss aversion, Overconfidence, Gender Differences. 